\title{
Transmission of Government Default Risk in the Eurozone
}

\author{
Anssi Kohonen \\ University of Helsinki and HECER
}

Discussion Paper No. 359

December 2012

ISSN 1795-0562

HECER - Helsinki Center of Economic Research, P.O. Box 17 (Arkadiankatu 7), FI-00014 University of Helsinki, FINLAND, Tel +358-9-191-28780, Fax +358-9-191-28781,

E-mail info-hecer@helsinki.fi, Internet www.hecer.fi 


\title{
Transmission of Government Default Risk in the Eurozone ${ }^{*}$
}

\begin{abstract}
The paper develops an easy-to-apply test for contagion. In order to address the main challenge of any contagion test, that of endogeneity, the testing is conducted in the structural vector autoregression (SVAR) framework where we assume the reduced form errors follow a mixed-normal distribution. This distributional assumption enables us to use a recently developed SVAR model identification method with no need to restrict any of the instantaneous linkages between the variables. In the empirical part of the paper, we apply our test to the eurozone's ten years government bond spreads over Germany. In this maturity, the bond spreads mainly reflect governments' default risk. The years we consider are 2005--2010, and we find evidence of contagion in the spreads. Furthermore, it appears that, during the beginning of the euro debt crisis, there was transmission of government default risk from Greece to the other countries. However, Greece was not the only source country of contagion.
\end{abstract}

JEL Classification: C1, C3, E4, F3, G1

Keywords: SVAR; contagion; interdependencies; hypothesis testing; sovereign spreads

Anssi Kohonen

Department of Political and Economic Studies

University of Helsinki

P.O. Box 17

FI-00014 University of Helsinki

FINLAND

e-mail: anssi.kohonen@helsinki.fi

* I want to thank professor Markku Lanne, Otto Kässi, and the participants to the CREATES lunch seminar for useful comments on the earlier version of this paper. I also want to thank the OP-Pohjola Group for their financial support for this research. Part of this research was carried out while I was visiting CREATES. I appreciate their hospitality. 


\section{Introduction}

Since the mid 1990's, the occurrence of contagion in the world's economic and financial press has multiplied heavily (Forbes, 2012). The term is often used to explain transmission of financial turmoil between countries; turmoil in one country causes turmoil elsewhere. Whereas the common parlance has remained a little unclear on how to actually define contagion, the academic research has tried to be more rigorous. And so, many theoretical models have been proposed to explain transmission of country or market specific shocks to other countries or markets. ${ }^{1}$

However, it is hard to estimate most of these theoretical models. For this reason, especially after the influential paper by Forbes and Rigobon (2002), the mainstream of the empirical research on contagion has taken a different approach. The empirical studies have made distinction between contagion and interdependence; the latter refers to the normal times linkages between the financial variables of any two countries whereas the former means any crisis-contingent structural change in the linkages ${ }^{2}$. This approach has been the motivation for many empirical papers; see for example Corsetti, Pericoli, and Sbracia (2005); Pesaran and Pick (2007); Billio and Caporin (2010); and Metiu (2012), only to a few to be mentioned.

In the next section we build an empirical test for discerning contagion from interdependence. The test is based on the Favero and Giavazzi (2002) contagion model in the structural vector autoregressive (SVAR) model framework. The Favero and Giavazzi model addresses the main challenge in the empirical contagion literature, that of endogeneity. Endogeneity rises because prices in the world's financial markets answer almost instantaneously to news. So, anyone wanting to test for contagion usually ends up working with a system of simultaneous equations. However, the general Favero and Giavazzi model is not identified as such

\footnotetext{
${ }^{1}$ For example, contagion could be a result of information asymmetries between investors (King and Wadhwani, 1990; Kodres and Pritsker, 2002); short-selling restrictions in global financial markets (Calvo and Mendoza, 2000); self-fulfilling investor beliefs (Masson, 1999); or international banks' and corporations' balance sheets transmitting idiosyncratic shocks between countries and sectors (Allen and Gale, 2000; Mendoza and Quadrini, 2010; Kiyotaki and Moore, 2002). There are several survey articles available on the theoretical and empirical literature; see, for example, Dornbusch, Park, and Claessens (2000); Pericoli and Sbracia (2003); Forbes and Rigobon (2001), and Forbes (2012).

${ }^{2}$ Some academics consider as contagion only such crisis-contingent changes that increase the correlation between, say, daily stock market returns of countries. Also, some papers refer to shiftor true contagion. Nevertheless, these all mean more-or-less the same thing, a structural break in the interdependencies. Notice that our definition of contagion, crisis-contingent structural changes in shock propagation mechanisms, includes also the so-called "flight-to-quality" effects where a crisis somewhere makes investors to sell assets in countries regarded as weak and to buy them in countries considered to be safe. This can decrease the correlation between the returns. For a discussion and criticism on the validity of the term contagion, see the introduction in Favero and Giavazzi (2002).
} 
and further assumptions are required. In their paper, Favero and Giavazzi end up restricting the parameter space. In contrast, our identification of their SVAR model is based on assuming the reduced form errors follow a mixed-normal distribution. Then we can use the recently proposed SVAR identification method by Lanne and Lütkepohl (2010). Unlike with the traditional SVAR identification methods that rely on restricting dependencies between the variables, the idea of Lanne and Lütkepohl is to use non-normalities in the data as an extra source of information. Because the main objective of a contagion test is to measure changes in the instantaneous dependencies between financial variables, it is of course a desirable feature of our test that we do not need to make any a priori restrictions on them. ${ }^{3}$

The application of the Lanne and Lütkepohl method relates our model to the SVAR identification literature that uses some specific particularity in data as a source of the needed extra information. For example, Rigobon (2003a) introduces a heteroskedasticity based identification method that has been successfully applied in the contagion-and the volatility spillover-literature (see, for example, Caporale, Cipollini, and Spagnolo (2005); Caporale, Cipollini, and Demetriades (2005); Rigobon (2002); Rigobon and Sack (2003)). However, unlike Lanne and Lütkepohl who assume the non-normalities are exhibited in the reduced form errors' joint distribution, Rigobon assumes heteroskedasticity in the structural shocks. However, because the original Favero and Giavazzi model assumes the structural shocks are homoskedastic but the reduced form errors might be heteroskedastic due to contagion, the Lanne-Lütkepohl method seems more favorable in our context.

In practice, our test boils down to searching for structural breaks in the SVAR model. It perhaps most closely resembles the "determinant of the changes in covariances" test proposed by Rigobon (2003b), and the multivariate contagion test of Dungey, Fry, Gonzalez-Hermosillo, and Martin (2005, 11-12). The former first calculates the covariance matrices (of the market returns) in normal and crisis times, then takes the changes in the covariances, and finally calculates the determinant of a changes-in-covariances matrix. If the determinant is zero, the paper argues, the shock propagation mechanisms have stayed stable during the crisis. Hence, there is not contagion. Rigobon's test, however, basically requires that we know which are the crisis countries and that some of the countries are known to be non-crisis countries. Our test is free of these requirements. We simply need to be able to identify the crisis periods from the normal times. This can usually be done more or less accurately. ${ }^{4}$ The latter test, that of Dungey and

\footnotetext{
${ }^{3}$ Of course, sometimes there are well justified institutional reasons for restrictions on (almost) instantaneous effects. For example, Billio and Caporin (2010) consider markets in different timezones.

${ }^{4}$ For examples of clear-cut crisis periods see, in addition to Rigobon's paper, Forbes and Rigobon (2002); Dungey, Fry, Gonzalez-Hermosillo, and Martin (2005); Corsetti, Pericoli, and
} 
the others, is based on a latent factor model. This model is perhaps best applicable for asset return time series with zero mean. Such series are usually obtained by taking the first differences of the variables. Once one is interested in investigating the financial variables in their level values, a (S)VAR framework is probably more suitable.

Section 3 applies our new test to the eurozone government bond spreads over the German government bond during the years 2005-2010. The countries included to the analysis are Ireland, Greece, Spain, Italy, and Portugal. In our analysis, we use spreads of the countries' ten years government bonds over Germany. These spreads mainly measure the risk of government default. Hence, our contagion test investigates whether there was transmission of government default risk in the eurozone during the beginning of the euro debt crisis. The beginning of the crisis is detected empirically. When testing for the stability of the pre-crisis linkages we find evidence of structural break in them, or contagion. By using the estimated mixture probability of the mixed-normal distribution as a weight, we also calculate weighted correlation coefficients of the country spreads both during the normal and the crisis periods. Because these coefficients automatically take into account the possible unconditional heteroskedasticities in the spreads' distributions, they are better suited for correlation analysis than the ones used in many of the earlier contagion studies. ${ }^{5}$

Finally, the last section summarizes our main findings and discussion. The section also briefly considers some of the pitfalls of the interdependence versus contagion approach.

\section{The Model}

This section first presents the contagion model of Favero and Giavazzi. It is a very general SVAR model that one is not able to identify as such. In their paper Favero and Giavazzi use specific zero restrictions to identify a version of their model and

\footnotetext{
Sbracia (2005).

${ }^{5}$ Perhaps the main insight of the Forbes and Rigobon (2002) paper was to underline that, because during crises unconditional variances of financial variables usually rise, conditional correlation coefficients calculated during the crisis are upwards biased. So, if the analysis is based on comparing the pre-crisis and the crisis time conditional correlations of returns, analysis that considers changes in these correlation coefficients as evidence of contagion might be biased. This was the approach of the earlier contagion research (see, for example, Calvo and Reinhart (1996); King and Wadhwani (1990); Lee and Kim (1994)). The higher-than-before correlation during a crisis could solely be a result of higher unconditional variance during the crisis, not of any new structural shock transmission channels. Hence, the conditional correlation coefficients need to be adjusted for heteroskedasticity. But the adjustment Forbes and Rigobon suggest assumes no endogeneity in the model. This is of course a very strong assumption.
} 
test for contagion in sovereign spreads. Their contagion test amounts to testing the statistical significance of market turmoil time dummies in all countries. The turmoil periods are determined by using specific threshold values for the realizations of the residuals of a standard reduced form vector autoregressive (VAR).

We take a different approach; we will first consider how contagion would demonstrate itself in the general Favero and Giavazzi SVAR model (henceforth, the FG model) and then develop an empirical model that we can identify and estimate. As it will be shown, testing contagion boils down to test for the stability of our empirical model. The identification of our empirical model is based on using nonnormalities in the sovereign spread series as an extra source of information.

\subsection{The underlying contagion model}

Denote country $i$ 's government bond yield in period $t$ as $y_{i t}$ and that of the German government bond as $y_{t}^{*}$. Country $i$ 's bond spread over Germany in period $t$ then becomes $s_{i t}=y_{i t}-y_{t}^{*}$. The FG model for $n \geq 2$ countries is the following:

$$
\mathbf{s}_{t}=\mathbf{A} \mathbf{s}_{t-1}+\mathbf{B}\left(\mathbf{I}_{n}+\mathbf{C D}_{t}\right) \varepsilon_{t}
$$

where $\mathbf{s}_{t}$ is the $(n \times 1)$ vector of the country spreads; $\mathbf{A}, \mathbf{B}$ and $\mathbf{C}$ are $(n \times n)$ coefficient matrices; and $\mathbf{I}_{n}$ is the $(n \times n)$ identity matrix. The matrix $\mathbf{D}_{t}=$ $\operatorname{diag}\left(d_{1 t}, \ldots, d_{n t}\right)$ is diagonal and includes country specific crisis dummies. All these dummies equal to zero during the normal times. But if there is a crisis in period $t$ that originates in country $i$, we will have $d_{i t}=1$ and $d_{j t}=0$ for all $j \neq i$. The $(n \times 1)$ vector $\varepsilon_{t}=\left[\varepsilon_{1 t}, \ldots, \varepsilon_{n t}\right]^{\prime}$ corresponds to the country specific structural shocks which are assumed to be uncorrelated of each other. Favero and Giavazzi assume the structural shocks are Gaussian, but we do not need assume any specific distribution for them. However, in order to normalize the SVAR model, we assume the structural shocks have variance equal to one ${ }^{6}$; so concisely, we assume $\varepsilon_{t} \sim\left(\mathbf{0}, \mathbf{I}_{n}\right)$.

Let us now consider how contagion demonstrates itself in this model framework and how it should be tested. For this purpose it is enough that we limit our discussion to the two countries case. Then, during normal times, when we have $d_{1 t}=d_{2 t}=0$, model (1) for two countries simplifies to

$$
\left[\begin{array}{l}
s_{1 t} \\
s_{2 t}
\end{array}\right]=\left[\begin{array}{ll}
a_{11} & a_{12} \\
a_{21} & a_{22}
\end{array}\right]\left[\begin{array}{l}
s_{1 t-1} \\
s_{2 t-1}
\end{array}\right]+\left[\begin{array}{ll}
b_{11} & b_{12} \\
b_{21} & b_{22}
\end{array}\right]\left[\begin{array}{l}
\varepsilon_{1 t} \\
\varepsilon_{2 t}
\end{array}\right]
$$

Clearly, the effect of the country 1 specific shock $\varepsilon_{1 t}$ to country 2 is equal to $b_{21}$. Similarly, the effect of country 2 specific shock to country 1 equals $b_{12}$. Hence,

\footnotetext{
${ }^{6}$ The unit variance assumption is a common way to normalize a SVAR model. Kilian (2011) discusses several possible ways to normalize such a model.
} 
these off-diagonal elements of the matrix $\mathbf{B}$ capture the interdependencies, the normal times instantaneous linkages between the countries' spreads.

Consider now a situation where a crisis originates, say, in country 1 . Then, during this period of market turmoil, because we have $d_{1 t}=1$ and $d_{2 t}=0$, model (1) becomes

$$
\left[\begin{array}{l}
s_{1 t} \\
s_{2 t}
\end{array}\right]=\left[\begin{array}{ll}
a_{11} & a_{12} \\
a_{21} & a_{22}
\end{array}\right]\left[\begin{array}{l}
s_{1 t-1} \\
s_{2 t-1}
\end{array}\right]+\left[\begin{array}{ll}
b_{11} & b_{12} \\
b_{21} & b_{22}
\end{array}\right]\left[\begin{array}{cc}
1+c_{11} & 0 \\
c_{21} & 1
\end{array}\right]\left[\begin{array}{l}
\varepsilon_{1 t} \\
\varepsilon_{2 t}
\end{array}\right],
$$

where the elements $c_{11}$ and $c_{21}$ are from the first column of the matrix C. Similarly, a crisis that originates in country $2\left(d_{1 t}=0\right.$ and $\left.d_{2 t}=1\right)$ results in the following model equation:

$$
\left[\begin{array}{l}
s_{1 t} \\
s_{2 t}
\end{array}\right]=\left[\begin{array}{ll}
a_{11} & a_{12} \\
a_{21} & a_{22}
\end{array}\right]\left[\begin{array}{l}
s_{1 t-1} \\
s_{2 t-1}
\end{array}\right]+\left[\begin{array}{ll}
b_{11} & b_{12} \\
b_{21} & b_{22}
\end{array}\right]\left[\begin{array}{cc}
1 & c_{12} \\
0 & 1+c_{22}
\end{array}\right]\left[\begin{array}{l}
\varepsilon_{1 t} \\
\varepsilon_{2 t}
\end{array}\right]
$$

where the elements $c_{12}$ and $c_{22}$ are now from the second column of the matrix C. Favero and Giavazzi conclude that it is then the off-diagonal elements of the matrix $\mathbf{C}$, here $c_{12}$ and $c_{21}$, that represent crisis-contingent structural changes in the propagation mechanisms of the structural shocks across countries. And so, according to them, ideally one should tests whether $c_{12}=c_{21}=0$ (no-contagion) or not (contagion). However, this is not exactly true. As the example below will demonstrate we would need to have all of the elements of the matrix $\mathbf{C}$ equal to zero not to have any contagion.

For example, consider equation (2) that gives the SVAR model when the crisis originates in country 1 . This equation can be written as

$$
\left[\begin{array}{l}
s_{1 t} \\
s_{2 t}
\end{array}\right]=\left[\begin{array}{ll}
a_{11} & a_{12} \\
a_{21} & a_{22}
\end{array}\right]\left[\begin{array}{l}
s_{1 t-1} \\
s_{2 t-1}
\end{array}\right]+\left[\begin{array}{ll}
b_{11}\left(1+c_{11}\right)+b_{12} c_{21} & b_{12} \\
b_{21}\left(1+c_{11}\right)+b_{22} c_{21} & b_{22}
\end{array}\right]\left[\begin{array}{l}
\varepsilon_{1 t} \\
\varepsilon_{2 t}
\end{array}\right] .
$$

The combined effect of country 1's structural shock to country 2 is then

$$
b_{21}\left(1+c_{11}\right)+b_{22} c_{21} .
$$

Clearly, even if we had $c_{21}=0$, this effect would not equal to $b_{21}$ as long as $c_{11} \neq 0$. By similar reasoning we can conclude that, when there is a crisis that originates in country 2, we need to have both $c_{12}$ and $c_{22}$ equal to zero for there not being any contagion (from country 2 to country 1 ). Also a common crisis or exogenous shock is possible, then we would have $d_{1 t}=d_{2 t}=1$. Clearly, also in this case the necessarily and sufficient condition for there not being contagion, that is structural changes in the instantaneous linkages between the spreads, is to have all elements of the matrix $\mathbf{C}$ equal to zero. So, a proper contagion test should test whether or not $\mathbf{C}=\mathbf{0}$. If it does, there is not contagion between the spreads. 


\subsection{The empirical models and the contagion test}

Unfortunately, one cannot identify the matrix $\mathbf{C}$ from the matrix $\mathbf{B}$ in model (1). So, directly testing the hypothesis of $\mathbf{C}=\mathbf{0}$ is not possible. Here, an indirect way is proposed. It amounts to estimating two separate empirical models; a restricted one that corresponds to the case of no contagion, and a unrestricted one where we allow for contagion. In the restricted model we force the linkages between the spreads to stay the same throughout normal and crisis times. In the unrestricted model we allow the linkages to change during a crisis. The restricted model corresponds to the case where $\mathbf{C}=\mathbf{0}$ and the unrestricted to the case where $\mathbf{C} \neq \mathbf{0}$.

The actual contagion test is then performed by testing the restricted model against the unrestricted one with the standard likelihood ratio (LR) test. Whenever the LR test does not reject the restricted model, we can conclude that $\mathbf{C}=\mathbf{0}$ and, so, there is not contagion between the countries during a crisis. For presentational purposes, we consider a case where we have a sample of $T$ observations with the first $T_{1}$ periods consisting of the normal times and the last $T_{2}=T-T_{1}$ periods being the crisis period. It is straightforward to adapt the framework for more complex situations.

\subsubsection{The restricted model: identification and estimation}

When $\mathbf{C}=\mathbf{0}$, model (1) simply becomes

$$
\mathbf{s}_{t}=\mathbf{A} \mathbf{s}_{t-1}+\mathbf{B} \varepsilon_{t} .
$$

The corresponding reduced form VAR model is then ${ }^{7}$

$$
\mathbf{s}_{t}=\mathbf{A} \mathbf{s}_{t-1}+\mathbf{u}_{t}
$$

where the $(n \times 1)$ reduced form error vector $\mathbf{u}_{t}=\mathbf{B} \boldsymbol{\varepsilon}_{t}$. This corresponds to the B-model framework of the SVAR models (for more details on the B-model, see, for example, Lütkepohl $(2007,362-64))$. The question is how to identify the structural shocks and, so, estimate the matrix $\mathbf{B}$.

We will follow the idea of Lanne and Lütkepohl (2010) and exploit non-normalities in the data to identify the model. We assume especially that $\mathbf{u}_{t}$ follows a mixednormal distribution, so that

$$
\mathbf{u}_{t}= \begin{cases}\mathbf{e}_{1 t} \sim N\left(\mathbf{0}, \boldsymbol{\Sigma}_{\mathbf{1}}\right) & \text { with probability } \quad \gamma \\ \mathbf{e}_{2 t} \sim N\left(\mathbf{0}, \boldsymbol{\Sigma}_{\mathbf{2}}\right) & \text { with probability } 1-\gamma\end{cases}
$$

where $N\left(\mathbf{0}, \boldsymbol{\Sigma}_{\mathbf{i}}\right)$ denotes a multivariate normal distribution with zero mean and $(n \times n)$ covariance matrix $\boldsymbol{\Sigma}_{\mathbf{i}}$. Hence, $\mathbf{e}_{1 t}$ and $\mathbf{e}_{2 t}$ are two serially independent

\footnotetext{
${ }^{7}$ Whereas Favero and Giavazzi assume a VAR model of lag order one, we will, in our empirical part, use empirical criteria to determine the correct lag length.
} 
Gaussian error vectors. For the mixture probability $\gamma \in(0,1)$ to be identifiable, one needs to assume that the covariance matrices $\Sigma_{1}$ and $\Sigma_{2}$ are (at least partly) distinct.

Lanne and Lütkepohl show that there exist a nonsingular $(n \times n)$ matrix $\mathbf{W}$ and a $(n \times n)$ diagonal matrix $\Psi=\operatorname{diag}\left(\psi_{1}, \ldots, \psi_{n}\right)$ with all diagonal elements being strictly positive, such that the covariance matrices in the mixed-normal distribution of equation (4) can be decomposed in the following way: $\boldsymbol{\Sigma}_{1}=\mathbf{W} \mathbf{W}^{\prime}$ and $\Sigma_{2}=\mathbf{W} \Psi \mathbf{W}^{\prime}$. This result follows from the covariance matrices being symmetric and positive definite (for details, see the appendix in the Lanne and Lütkepohl paper). Provided that all the elements $\psi_{i}$ are distinct from each other, the matrix $\mathbf{W}$ is unique (apart from changing the signs of the elements in every column).

The covariance matrix of the reduced form errors can then be written as

$$
\boldsymbol{\Sigma}_{\mathbf{u}}=\gamma \boldsymbol{\Sigma}_{\mathbf{1}}+(1-\gamma) \boldsymbol{\Sigma}_{\mathbf{2}}=\mathbf{W}\left(\gamma \mathbf{I}_{n}+(1-\gamma) \Psi\right) \mathbf{W}^{\prime}
$$

On the other hand, from the assumption $\mathbf{u}_{t}=\mathbf{B} \boldsymbol{\varepsilon}_{t}$ it follows that

$$
\Sigma_{\mathbf{u}}=\mathbf{B} \Sigma_{\varepsilon} \mathbf{B}^{\prime}=\mathbf{B B}^{\prime}
$$

where we have applied our normalizing assumption of $\boldsymbol{\Sigma}_{\varepsilon}=\mathbf{I}_{n}$. Comparing this with the covariance matrix in equation (5) allows us to choose

$$
\mathbf{B}=\mathbf{W}\left(\gamma \mathbf{I}_{n}+(1-\gamma) \Psi\right)^{1 / 2}
$$

Once we also assume that the elements $\left\{\psi_{1}, \ldots, \psi_{n}\right\}$ are in some pre-defined order, for example in the descending order, on the main diagonal of the matrix $\Psi$, the matrix B is unique (Lanne, Lütkepohl, and Maciejowska, 2010).

Although this last assumption concerning the pre-defined order of the $\psi_{i}$ 's is crucial for us to be able to uniquely identify the SVAR model, it does not affect the generality of our test. This can be seen in the following way: first, as Kohonen (2012) shows, whenever we choose $\mathbf{B}=\mathbf{W}\left(\gamma \mathbf{I}_{n}+(1-\gamma) \boldsymbol{\Psi}\right)^{1 / 2}$, where the elements on the diagonal of the matrix $\boldsymbol{\Psi}$ are in some pre-specified order, we could as well choose $\hat{\mathbf{B}}=\left(\mathbf{W P}^{\prime}\right)\left(\gamma \mathbf{I}_{n}+(1-\gamma) \mathbf{P} \boldsymbol{\Psi} \mathbf{P}^{\prime}\right)^{1 / 2}$ as our B-matrix. Here, $\mathbf{P}$ is an arbitrary $(n \times n)$ permutation matrix. Second, given that we assume the underlying FG model holds, using any $\hat{\mathbf{B}}$ instead of $\mathbf{B}$ simply reshuffles the order of the structural shocks in the vector $\varepsilon_{t}$. To see this, notice that the part $\left(\gamma \mathbf{I}_{n}+(1-\gamma) \mathbf{P} \boldsymbol{\Psi} \mathbf{P}^{\prime}\right)^{1 / 2}=\left(\mathbf{P}\left(\gamma \mathbf{I}_{n}+(1-\gamma) \mathbf{\Psi}\right) \mathbf{P}^{\prime}\right)^{1 / 2}$ in $\hat{\mathbf{B}}$ is diagonal, so it equals to $\mathbf{P}\left(\gamma \mathbf{I}_{n}+(1-\gamma) \mathbf{\Psi}\right)^{1 / 2} \mathbf{P}^{\prime}$. It follows that $\hat{\mathbf{B}}=\mathbf{B} \mathbf{P}^{\prime}$ (remember that $\mathbf{P}$ is orthogonal, and so $\left.\mathbf{P} \mathbf{P}^{\prime}=\mathbf{I}_{n}\right)$. Hence, the matrix $\hat{\mathbf{B}}$ is simply a column-wise permutation of B. On the other hand, denote as $\hat{\boldsymbol{\varepsilon}}_{t}$ the structural shocks that correspond to the matrix $\hat{\mathbf{B}}$. So, we have $\mathbf{u}_{t}=\mathbf{B} \boldsymbol{\varepsilon}_{t}=\hat{\mathbf{B}} \hat{\boldsymbol{\varepsilon}}_{t}$, from where it follows that

$$
\hat{\varepsilon}_{t}=(\hat{\mathbf{B}})^{-1} \mathbf{B} \varepsilon_{t}=\left(\mathbf{B} \mathbf{P}^{\prime}\right)^{-1} \mathbf{B} \varepsilon_{t}=\mathbf{P}^{\prime-1} \mathbf{B}^{-1} \mathbf{B} \varepsilon_{t}=\mathbf{P} \varepsilon_{t},
$$


where $\mathbf{P}^{\prime-1}=\mathbf{P}$ is a result from $\mathbf{P}$ being orthogonal. So, $\hat{\boldsymbol{\varepsilon}}_{t}$ is simply a row-wise permutation on the vector $\varepsilon_{t}$.

Hence, there are $n$ ! possible permutations of the B-matrix, and as many ways to identify the SVAR model. Only one of these permutations will coincide with the situation where the country one specific shock $\varepsilon_{1 t}$ is placed first, the country two specific shock $\varepsilon_{2 t}$ second, etc. But as long as we are simply interested in testing the stability of the effects of the structural shocks (as we are in this paper), we do not need to identify this "correct" permutation. It is enough to assume that our structural model in equation (1), augmented with the distributional assumption (4), is correct-this is something that we naturally assume in the first place-and simply work with some predefined order of the elements $\left\{\psi_{1}, \ldots, \psi_{n}\right\}$.

Given our distributional assumption (4), the restricted model in equation (3) can be estimated with the method of maximum likelihood (ML). After taking into account the decompositions of the covariance matrices $\boldsymbol{\Sigma}_{1}$ and $\boldsymbol{\Sigma}_{2}$ with respect to the parameters $\gamma, \mathbf{W}$, and $\mathbf{\Psi}$; the conditional density of $\mathbf{s}_{t}$ becomes (for details, see the paper by Lanne and L'utkepohl)

$$
\begin{aligned}
f\left(\mathbf{s}_{t} \mid \mathbf{s}_{t-1}\right)= & \gamma \operatorname{det}(\mathbf{W})^{-1} \exp \left\{-\frac{1}{2}\left(\mathbf{s}_{t}-\mathbf{A} \mathbf{s}_{t-1}\right)^{\prime}\left(\mathbf{W} \mathbf{W}^{\prime}\right)^{-1}\left(\mathbf{s}_{t}-\mathbf{A} \mathbf{s}_{t-1}\right)\right\}+ \\
& +(1-\gamma) \operatorname{det}(\mathbf{W})^{-1} \operatorname{det}(\mathbf{\Psi})^{-1 / 2} \times \\
& \exp \left\{-\frac{1}{2}\left(\mathbf{s}_{t}-\mathbf{A} \mathbf{s}_{t-1}\right)^{\prime}\left(\mathbf{W} \boldsymbol{\Psi} \mathbf{W}^{\prime}\right)^{-1}\left(\mathbf{s}_{t}-\mathbf{A} \mathbf{s}_{t-1}\right)\right\},
\end{aligned}
$$

where we have ignored the constant terms of a Gaussian density function. By collecting all the parameters $\mathbf{A}, \gamma, \mathbf{W}$, and $\boldsymbol{\Psi}$ into the $\boldsymbol{\theta}$, the log-likelihood function of the restricted model becomes

$$
l(\boldsymbol{\theta})=\sum_{t=1}^{T} \log f\left(\mathbf{s}_{t} \mid \mathbf{s}_{t-1}\right) .
$$

This can be maximized with the standard optimization algorithms.

\subsubsection{The unrestricted model: identification and estimation}

Let us now consider the unrestricted case where we allow for $\mathbf{C} \neq \mathbf{0}$. Write open the parenthesis in model (1) to get the following version of the SVAR model:

$$
\mathbf{s}_{t}=\mathbf{A s}_{t-1}+\left(\mathbf{B}+\mathbf{B C D}_{t}\right) \varepsilon_{t} .
$$

So clearly, during the normal times as $\mathbf{D}_{t}=\mathbf{0}$, the unrestricted model corresponds to the restricted model of the previous section, and we can write

$$
\begin{aligned}
\mathbf{s}_{t} & =\mathbf{A} \mathbf{s}_{t-1}+\mathbf{B} \varepsilon_{t} \\
& =\mathbf{A} \mathbf{s}_{t-1}+\mathbf{u}_{t}^{N},
\end{aligned}
$$


where the $(n \times 1)$ vector $\mathbf{u}_{t}^{N}$ corresponds to the reduced form errors during the normal times as we have assumed $\mathbf{u}_{t}^{N}=\mathbf{B} \varepsilon_{t}$.

During the crisis times, however, $\mathbf{D}_{t} \neq \mathbf{0}$ and, so, after redefining $\tilde{\mathbf{B}}=\mathbf{B}+$ $\mathbf{B C D}_{t}$, the unrestricted model becomes

$$
\begin{aligned}
\mathbf{s}_{t} & =\mathbf{A} \mathbf{s}_{t-1}+\tilde{\mathbf{B}} \varepsilon_{t} \\
& =\mathbf{A} \mathbf{s}_{t-1}+\mathbf{u}_{t}^{C},
\end{aligned}
$$

where $\mathbf{u}_{t}^{C}=\tilde{\mathbf{B}} \boldsymbol{\varepsilon}_{t}$ is the $(n \times 1)$ vector of the reduced from errors. Here, whenever $\mathbf{C} \neq \mathbf{0}$, we have $\tilde{\mathbf{B}} \neq \mathbf{B}$. In such a case the unrestricted model differs from the restricted one during the crisis period because of contagion $(\mathbf{C} \neq \mathbf{0})$. In contrast, whenever $\mathbf{C}=\mathbf{0}$, and so there is not contagion, $\tilde{\mathbf{B}}=\mathbf{B}$ and the model (7) equals the restricted model (3) also during the crisis times. Hence, whenever $\mathbf{C}=\mathbf{0}$, the unrestricted model corresponds to the restricted model both during the normal and the crisis times.

Our test for contagion then boils down to testing with the LR test how well the restricted model describes the data during the full sample period, including both the normal and crisis times, against the unrestricted model. In essence, we then indirectly test the statistical significance of the matrix C. Assuming stationarity, we can refer to the standard ML asymptotic theory and know that the LR test statistic follows $\chi^{2}$-distribution with $n^{2}+n+1$ degrees of freedom. The reason for that specific number of degrees of freedom is evident after the following discussion.

The reduced form VAR model corresponding to the unrestricted SVAR model can be written concisely in the following way:

$$
\mathbf{s}_{t}=\mathbf{A} \mathbf{s}_{t-1}+\iota_{N} \mathbf{u}_{t}^{N}+\iota_{C} \mathbf{u}_{t}^{C},
$$

where the indicator variables $\iota_{N}$ and $\iota_{C}$ equal one during the normal and crisis times, respectively; and as already mentioned $\mathbf{u}_{t}^{N}\left(\mathbf{u}_{t}^{C}\right)$ corresponds to the reduced form errors during the normal (crisis) times. Because the underlying assumption is that $\mathbf{u}_{t}^{N}=\mathbf{B} \varepsilon_{t}$ and $\mathbf{u}_{t}^{C}=\tilde{\mathbf{B}} \varepsilon_{t}$, we can now generalize the identification method from the previous section by assuming that the normal and crisis times error vectors follow mixed-normal distributions

$$
\mathbf{u}_{t}^{N}=\left\{\begin{array}{ccc}
\mathbf{e}_{1 t}^{N} \sim N\left(\mathbf{0}, \mathbf{W}_{1} \mathbf{W}_{1}^{\prime}\right) & \text { with probability } & \gamma_{1} \\
\mathbf{e}_{2 t}^{N} \sim N\left(\mathbf{0}, \mathbf{W}_{1} \mathbf{\Psi}_{1} \mathbf{W}_{1}^{\prime}\right) & \text { with probability } & 1-\gamma_{1}
\end{array}\right.
$$

and

$$
\mathbf{u}_{t}^{C}=\left\{\begin{array}{clc}
\mathbf{e}_{1 t}^{C} \sim N\left(\mathbf{0}, \mathbf{W}_{2} \mathbf{W}_{2}^{\prime}\right) & \text { with probability } & \gamma_{2}, \\
\mathbf{e}_{2 t}^{C} \sim N\left(\mathbf{0}, \mathbf{W}_{2} \mathbf{\Psi}_{2} \mathbf{W}_{2}^{\prime}\right) & \text { with probability } & 1-\gamma_{2} .
\end{array}\right.
$$

For both periods, the normal and crisis, the conditional density function of $\mathbf{s}_{t}$ is similar to the restricted model's conditional density function in equation (6) with 
only the obvious changes in the indexes of the parameters $\gamma, \mathbf{W}$, and $\boldsymbol{\Psi}$. Hence, the joint conditional density of $\mathbf{s}_{t}$ can be written as

$$
f\left(\mathbf{s}_{t} \mid \mathbf{s}_{t-1}\right)=\iota_{N} f^{N}\left(\mathbf{s}_{t} \mid \mathbf{s}_{t-1}\right)+\iota_{C} f^{C}\left(\mathbf{s}_{t} \mid \mathbf{s}_{t-1}\right),
$$

where $f^{N}(\cdot)$ and $f^{C}(\cdot)$ denote the densities during the normal and crisis times, respectively.

Again, after collecting all the model parameters into the vector $\hat{\boldsymbol{\theta}}$, and because we have assumed that the $T_{1}$ first periods corresponds to the normal period and the $T_{2}$ last periods corresponds to the crisis times, the log-likelihood function becomes

$$
\begin{aligned}
l(\hat{\boldsymbol{\theta}}) & =\sum_{t=1}^{T} \log f\left(\mathbf{s}_{t} \mid \mathbf{s}_{t-1}\right) \\
& =\sum_{t=1}^{T_{1}} \log f^{N}\left(\mathbf{s}_{t} \mid \mathbf{s}_{t-1}\right)+\sum_{t=T_{1}+1}^{T_{2}} \log f^{N}\left(\mathbf{s}_{t} \mid \mathbf{s}_{t-1}\right) .
\end{aligned}
$$

Like with the restricted model, the standard nonlinear optimization algorithms are applicable to maximize this function. Notice however that in practice both of the time intervals $T_{1}$ and $T_{2}$ need to be long enough so that all the parameters can be estimated. This rules out very short crisis periods. Also, now it is easy to see the reason for the specific number of the degrees of freedom of the asymptotic $\chi^{2}$ distribution for the LR test statistic. The restricted model of the previous section actually corresponds to the situation where we have restricted the parameters of the model in this section in the following way: $\mathbf{W}_{1}=\mathbf{W}_{2}, \gamma_{1}=\gamma_{2}$, and finally $\boldsymbol{\Psi}_{1}=\boldsymbol{\Psi}_{2}$. This means in total $n^{2}+n+1$ restrictions on to the parameter space.

\section{Testing contagion in the eurozone government bonds}

In this section, we apply our contagion test for the eurozone government bond data $^{8}$. Our data covers the years 2005-2010 and includes the daily observations of the government bond spreads over Germany. The spreads are calculated from the secondary market yields. The bond maturity we have chosen is ten years. In this maturity the spreads basically measure the governments' default risk (Favero and Missale, 2012). The empirical research question is then if there was contagion of default risk across the countries during the beginning of the recent euro debt crisis. The countries included into our analysis are Ireland, Greece, Spain, Italy, and Portugal (see figure 1).

\footnotetext{
${ }^{8}$ The government bond yields are from the Eurostat database. The US. corporate bond yields are from the St. Louis Fed's FRED-database.
} 


\section{INSERT FIGURE 1 AROUND HERE.}

\subsection{Determination of the crisis period}

In order to apply our test we first need to determine the normal and crisis periods. In figure 1 we see that until the mid 2007 the government bond spreads remained stable and near zero. After this the spreads started to slowly increase but still stayed close to each other. This first period of increasing spreads culminated in the beginning of 2009. According to Mody and Sandri (2012) the period from the mid 2007 to January 2009 consists of the first two phases of the euro debt crisis. During the period between July 2007 and March 2008 (the rescue of Bear Stearns) the financial distress was transmitted from the US banking sector to the eurozone banking sector. During the second phase, between March 2008 to January 2009, the troubles of the eurozone banks started increasingly to raise the euro government bond spreads because investors began to anticipate the possible extra stress on the government finances from a public bailout of banks.

In January 2009 the Irish government nationalized Anglo Irish Bank (AIB). This decision marks the start of what Mody and Sandri call the third phase of the euro debt crisis. During this phase the banking sector distress and the sovereign default risk became further intertwined with not only banks' troubles raising their home government's bond spread but also the government bond spreads increasing the distress in the national banking sectors. As figure 1 shows, the first reaction of the government bond spreads to the nationalization of AIB was to start decreasing and converging again. However, this period of relative calm lasted only for a short period of time. During the last part of 2009, especially the Greek, Irish, and Portuguese spreads started a massive increase.

We can then roughly say that, from our perspective, there are two distinct crisis periods. The first starts in the mid 2007 and lasts until the end of January 2009. This period is characterized with a common shock to the government bond spreads. The common shock is the rise in the global investor risk aversion and increased worry on the stability of the rich world banking sector. This interpretation is supported by the evolution of the spread between the US BBB and AAA credit rated corporate bond yields. This spread is often used to measure the global market attitude towards risk (Favero and Missale, 2012). As figure 1 shows, this spread increased jointly with the government bond spreads between the mid 2007 and the beginning of 2009. But during the latter part of 2009 and in 2010 the US corporate spread stayed stable while the euro government bond spreads began to increase. So, during our second crisis period, from February 2009 to the end of 2010, that covers the end of our sample period, it is not anymore common shocks that drive the crisis but the eurozone country specific shocks.

Following the discussion above, we divide the sample period into three distinct 
phases: normal times from 2005 to June 2007, global crisis from July 2007 to January 2009, and local euro crisis from January 2009 to 2010. All in all, the crisis periods together last for the last three and half years of our sample. The classification is supported with the time series in figure 2. The figure depicts for each country the average correlation of its spread with the rest of the countries' spreads. The correlation coefficients are calculated with a rolling six months time window. Until the mid 2007 the average correlations were roughly around 0.30 . During the last part of 2007, the correlation coefficients increased to between 0.40-0.80. And for the last three years of our sample, 2008-2010, the average correlation coefficients are almost without interruption at around 0.85 and stay quite close to each other. So, from the point of view of the correlation coefficients of the country spreads, both the global and the euro crisis phases have the same effect of increasing the dependencies between the countries. The actual euro debt crisis then consists of both of the crisis periods, the global and the local.

\section{INSERT FIGURE 2 AROUND HERE.}

\subsection{Testing contagion}

Based on out discussion in section 2.1, we have now two options to test whether the matrix $\mathbf{C}=\mathbf{0}$, and hence whether these was contagion between the government bond spreads during the beginning of the euro debt crisis. The first option is to consider only the normal times (January 2005-June 2007) versus the global phase of the euro crisis (July 2007-January 2009). Because the global crisis phase corresponds to a crisis driven by common shocks, in the FG model we would have then

$$
d_{\mathrm{IRE}, t}=d_{\mathrm{GRE}, t}=d_{\mathrm{SPA}, t}=d_{\mathrm{ITA}, t}=d_{\mathrm{POR}, t}=1,
$$

for $t$ in between July 2007-January 2009. And so, we can indirectly test whether or not $\mathbf{C}=\mathbf{0}$ by estimating the restricted and the unrestricted empirical models up until January 2009. This alternative leaves the end of our sample period (February 2009-December 2010) unused. Optionally, we can use the whole sample period of January 2005-December 2010 and simply consider the period from July 2007 onwards as the crisis periods. Let us do both.

Before testing, we need to determine the lag order of the (S)VAR model. This is chosen to be equal to two. The reason for this choice is that, although the Bayesian information criterion suggests using the order of one when the unrestricted model is estimated for the full sample period 2005-2010, model diagnostics with lag orders one and two support using the latter. When only the first order VAR model is used, the residuals exhibit very clear signs of remaining autocorrelation. With the lag order of two, the situation is much better and we can reject the null-hypothesis of remaining autocorrelation for at least the majority of the residuals (see section 
3.3 below). So, the actual restricted model corresponding to the null-hypothesis of no-contagion is

$$
\mathbf{s}_{t}=\mathbf{A}_{1} \mathbf{s}_{t-1}+\mathbf{A}_{2} \mathbf{s}_{t-2}+\mathbf{u}_{t}
$$

and the estimated unrestricted model corresponding to the alternative hypothesis of contagion becomes

$$
\mathbf{s}_{t}=\mathbf{A}_{1} \mathbf{s}_{t-1}+\mathbf{A}_{2} \mathbf{s}_{t-2}+\iota_{N} \mathbf{u}_{t}^{N}+\iota_{C} \mathbf{u}_{t}^{C} .
$$

The reduced from errors $\mathbf{u}_{t}, \mathbf{u}_{t}^{N}$ and $\mathbf{u}_{t}^{C}$ are assumed to follow the mixed-normal distributions (4), (9), and (10), respectively. The indicator variable $\iota_{N}$ equals one during the selected normal time period, 2005-June 2007, and $\iota_{C}$ during the crisis period.

In the first alternative, that of testing contagion by using only the global phase of the euro crisis, testing the restricted empirical model (11) against the unrestricted empirical model (12) with the LR test yields the value 508.3 for the test statistics. This is clearly greater than the critical values of the $\chi^{2}$-distribution with 31 degrees of freedom at any common significance level. For example, the critical value with the $5 \%$ significance level is 45.0 . Hence, we can conclude that the data speaks against the null-hypothesis of $\mathbf{C}=\mathbf{0}$. And so, there is evidence of contagion in the bond spreads. The actual parameter estimates of the restricted and unrestricted models are reported in the appendix (tables 3 and 4).

Given that the null-hypothesis of no-contagion is already rejected when we consider only the global crisis phase of the euro crisis, it is not a surprise that the null-hypothesis is also rejected when we consider the whole sample period from 2005 to 2010 and the crisis period being between July 2007-2010. The LR test statistic gets value 1435.1 when we again test the restricted model (11) against the unrestricted empirical model (12). The actual parameter estimates of both of the models can again be found from the appendix (tables 5 and 6 ). There is not too much sense in calculating the B-matrices of the normal and crisis times because we do not have any extra information to identify the correct permutation of the Bmatrices (see the discussion in the middle of section 2.2.1). However, what we can do, in order to continue our empirical analysis a little further, is to calculate what I call (mixture probability) weighted correlation coefficients between the country spreads for both the normal times (2005-June 2007) and the crisis times (July 2007-2010).

The normal and crisis period conditional weighted correlation coefficients between the spreads of countries $i$ and $j$ are calculated in the following way: consider, for example, the normal times. The reduced from error vector $\mathbf{u}_{t}^{N}$ is assumed to follow the mixed-normal distribution (9) with the mixture probability $\gamma_{1}$. Denote the corresponding normal distributions as $N\left(\mathbf{0}, \boldsymbol{\Sigma}_{1, N}\right)$ and $N\left(\mathbf{0}, \boldsymbol{\Sigma}_{2, N}\right)$, where $\boldsymbol{\Sigma}_{1, N}=\mathbf{W}_{1} \mathbf{W}_{1}^{\prime}$ and $\boldsymbol{\Sigma}_{2, N}=\mathbf{W}_{2} \Psi_{1} \mathbf{W}_{2}^{\prime}$. First, we need to calculate the conditional 
correlation coefficients between the country $i$ and $j$ spreads according to both of these normal distributions, denote them by $r_{i j, N}^{(1)}$ and $r_{i j, N}^{(2)}$, for the covariance matrices $\boldsymbol{\Sigma}_{1, N}$ and $\boldsymbol{\Sigma}_{2, N}$, respectively. The conditional weighted correlation coefficient $r_{i j}^{(w)}$ between the country $i$ 's and $j$ 's spreads during the normal time period is then acquired simply by weighting the two conditional correlation coefficients by the mixture probability $\gamma_{1}$ :

$$
r_{i j, N}^{(w)}=\gamma_{1} \cdot r_{i j, N}^{(1)}+\left(1-\gamma_{1}\right) \cdot r_{i j, N}^{(2)} .
$$

In the similar way we can calculate the conditional weighted correlation coefficient $r_{i j, C}^{(w)}$ for the spreads of the countries $i$ and $j$ during the crisis times. This is based on the normal distributions and the mixture probability of the crisis time period's mixture normal distribution (10).

For each country pair $i$ and $j$ we can then compare the conditional weighted correlations coefficients of their spreads during the normal times $\left(r_{i j, N}^{(w)}\right)$ versus the crisis times $\left(r_{i j, C}^{(w)}\right)$. If for example

$$
r_{i j, N}^{(w)}<r_{i j, C}^{(w)}
$$

and so the spreads of the countries $i$ and $j$ have become more correlated during the crisis, and if at the same time country $i$ 's spread has increased a lot, we have grounds to suspect that it is the default risk of country $i$ that has been transmitted also to the country $j$ 's spread. Alternatively, we could have

$$
r_{i j, N}^{(w)}>r_{i j, C}^{(w)},
$$

and so the correlation has decreased during the crisis, which could be an indication of "flight-to-safety" effect as investors consider either of the countries $i$ or $j$ as much safer than the other. Notice that because our model allows for greater (or smaller) unconditional spread volatility during the crisis period, our conditional weighted correlation coefficients are automatically adjusted for heteroskedasticity. This way, comparing $r_{i j, N}^{(w)}$ against $r_{i j, C}^{(w)}$ is not subject to the critique presented by Forbes and Rigobon (2002) against the earlier comparison studies of the normal times correlation coefficients against the crisis times correlation coefficients between selected financial variables (see footnote 5). However, it must be added that, as the model diagnostic analysis suggests, our model do not adequately model in all heteroskedasticity in the data.

Table 1 shows the conditional weighted correlation coefficients of the countries spreads in the normal times (2005-June 2007) and the crisis times (July 20072010). These are based on the unrestricted model (12) that was estimated using the full sample period 2005-2010. In the table, those conditional weighted correlation coefficients of the crisis times are highlighted with bold font that show an 
Table 1: Normal and crisis period conditional weighted correlation coefficients of country spreads for normal and crisis periods

\begin{tabular}{|c|c|c|c|c|}
\hline & $\begin{array}{l}\text { Greece } \\
\text { Normal | Crisis }\end{array}$ & $\begin{array}{l}\text { Spain } \\
\text { Normal | Crisis }\end{array}$ & $\begin{array}{l}\text { Italy } \\
\text { Normal | Crisis }\end{array}$ & $\begin{array}{l}\text { Portugal } \\
\text { Normal | Crisis }\end{array}$ \\
\hline Ireland & \begin{tabular}{l|l|}
0.24 & $\mathbf{0 . 4 5}$
\end{tabular} & \begin{tabular}{l|l|l}
0.49 & 0.46
\end{tabular} & \begin{tabular}{l|l}
0.55 & $\mathbf{0 . 5 9}$
\end{tabular} & \begin{tabular}{l|l}
0.59 & $\mathbf{0 . 6 8}$
\end{tabular} \\
\hline Greece & - & $0.35 \mid \mathbf{0 . 4 4}$ & $0.49 \mid \mathbf{0 . 6 3}$ & $0.25 \mid \mathbf{0 . 4 8}$ \\
\hline Spain & - & - & $0.56 \mid \mathbf{0 . 6 1}$ & $0.57 \mid 0.57$ \\
\hline Italy & - & - & - & $0.57 \mid \mathbf{0 . 6 9}$ \\
\hline \multicolumn{5}{|c|}{$\begin{array}{l}\text { The calculations are based on the estimated unrestricted model (12) for the full sample } \\
\text { period } 2005-2010 .\end{array}$} \\
\hline \multicolumn{5}{|c|}{ The normal (crisis) period corresponds to 2005-June 2007 (July 2007-2010). } \\
\hline \multicolumn{5}{|c|}{ The bold crisis time coefficients indicate an increase from the normal times. } \\
\hline \multicolumn{5}{|c|}{$\begin{array}{l}\text { For details on calculating the weighted correlation coefficients, see equation (13) and } \\
\text { the discussion around it. }\end{array}$} \\
\hline
\end{tabular}

increase from the normal times. Clearly, the majority of the country pairs see the correlation between their spreads to increase during the euro debt crisis. The exceptions are the pair Spain-Portugal whose coefficient stays the same and the pair Spain-Ireland whose coefficient decreases slightly during the crisis. These results would suggest that, during the beginning of the euro debt crisis, there was not transmission of government default risk from either Portugal or Ireland to Spain, and vice versa.

On the other hand, Greece is the only country that sees its correlation coefficient to increase with all the other countries; in percentages, the increase varies from $26 \%$ against Spain to $95 \%$ against Portugal. This observation, together with the fact that it is the Greek government bond spread that increases the most during the beginning of the euro debt crisis (see figure 1), suggests that there happened transmission of the risk of government default from Greece to others. However, also Portugal saw relatively large increases in its weighted correlation coefficients both against Ireland and Italy. So, these results would suggest that, although there seemed to be contagion from the Greek country spreads to the others' spreads, the transmissions of the country default risk were more complex than only from this one source country to the others.

\subsection{Model diagnostics}

For models like ours where we assume that the reduced form errors follow a mixednormal distribution, it is best to base the model diagnostic analysis on quantile 
residuals $^{9}$ (Kalliovirta, 2012). In order to illustrate the idea behind the quantile residuals, assume a univariate random variable $v_{t}$ that follows a mixed-normal distribution;

$$
v_{t}=\left\{\begin{array}{cl}
e_{1 t} \sim N\left(0, \sigma_{1}^{2}\right) & \text { with probability } \quad \gamma \\
e_{2 t} \sim N\left(0, \sigma_{2}^{2}\right) & \text { with probability } 1-\gamma .
\end{array}\right.
$$

Here, the random variables $e_{1 t}$ and $e_{2 t}$ are assumed to be independent of each other and normally distributed with variances $\sigma_{1}^{2}$ and $\sigma_{1}^{2}$, respectively; $\gamma$ is again the mixture probability. The cdf of $v_{t}$ can be written

$$
F\left(v_{t}\right)=\gamma \cdot \Phi\left(\frac{v_{t}}{\sigma_{1}}\right)+(1-\gamma) \cdot \Phi\left(\frac{v_{t}}{\sigma_{2}}\right)
$$

where $\Phi(\cdot)$ is the cdf of the standard normal distribution. The quantile residual $q r_{t}$ is then

$$
q r_{t}=\Phi^{-1}\left(F\left(v_{t}\right)\right),
$$

where $\Phi^{-1}(\cdot)$ is the inverse of the cdf of the standard normal distribution. If the model is correctly specified the quantile residuals should be independent, homoskedastic and follow standard normal distribution. In our diagnostics we use the multivariate specification of quantile residuals from Kalliovirta and Saikkonen (2010).

The diagnostic is based on the unrestricted model for the full sample period 2005-2010, the model whose parameter estimates are reported in table 6. Figure 3 shows the quantile-to-quantile plots (QQ-plots) that separately compare the empirical distributions of our five quantile residuals to the standard normal distribution. All of the residuals show some signs of skewness at their tails and the first and fourth have clear outliers. Also, the plot of the third residual is a little bit steeper than the theoretical line. However, overall it seems that the theoretical distribution depicts the empirical distributions relatively fine. Hence, this supports our model.

Table 2 in its turn investigates the remaining autocorrelation in our quantile residual series. The table reports the p-values of Ljung \& Box test statistic (as suggested by Palm and Vlaar (1997)) with using three different lag lengths. All of the series were tested independently, so the test do not consider the crosscorrelations between the residuals. For the first and second residual there is strong evidence against remaining autocorrelation. Also, the results for the fourth residual give some support to consider our model to be adequate. However, for the third and

\footnotetext{
${ }^{9}$ For example Dunn and Smyth (1996) and Palm and Vlaar (1997) consider univariate quantile residuals. For an extensive discussion on the use of and the different names of quantile residuals in literature, see Kalliovirta (2012).
} 
Table 2: Significance of autocorrelation in quantile residuals: The p-values of the Ljung \& Box test statistic with different lag lengths $h$

\begin{tabular}{c|c|c|c}
\hline \hline & \multicolumn{3}{|c}{ Lag length $h$} \\
& $\mathbf{1 0}$ & $\mathbf{2 0}$ & $\mathbf{3 0}$ \\
\hline$q r_{t}^{(1)}$ & 0.13 & 0.08 & 0.32 \\
$q r_{t}^{(2)}$ & 0.97 & 0.95 & 0.78 \\
$q r_{t}^{(3)}$ & 0.00 & 0.00 & 0.03 \\
$q r_{t}^{(4)}$ & 0.04 & 0.08 & 0.00 \\
$q r_{t}^{(5)}$ & 0.00 & 0.00 & 0.00 \\
\hline \hline
\end{tabular}

fifth residuals, the p-values of the null-hypothesis of no-autocorrelation are almost uniformly zero. Overall, however, the results in table 2 are a huge improvement from the SVAR model with only one lagged value of the dependent variable $\mathbf{s}_{t}$ (results are not reported here). Then almost all p-values of the Ljung \& Box test statistic are 0.00. Also, some of the small p-values in table 2 might reflect the fact that the quantile residuals show evidence of conditional heteroskedasticity. When testing conditional heteroskedasticity with the Ljung \& Box test statistic for the squared demeaned quantile residuals, all the residual series have p-values equal to 0.00 at all of the lag lengths 10, 20 and 30 of the test. Clearly, our model do not adequately take into account the changing volatility in the spreads.

Adding an additional lag order to our SVAR model might still alleviate autocorrelation (and perhaps conditional heteroskedasticity) in the quantile residuals. However, our model is already quite large and one extra lag of the dependent variable would add 36 parameters to our model. This said, and considering the support from the QQ-plots, I tempted to feel that our model adequately describes the data.

\section{Concluding remarks}

The theoretical contribution of this paper has been to develop an easy-to-apply test for contagion that takes into account the main challenge of any contagion test, that of endogeneity. The test builds on an established SVAR model that we extend into an identifiable empirical model. The main extension is to allow the reduced from errors of the corresponding VAR model to follow a mixed-normal distribution. Hence, our model allows for some degree of heteroskedasticity in the variables. This distributional assumption enables us to apply a recently proposed SVAR identification method. The main advantage of the identification method is that it allows us to avoid making any restrictions on the instantaneous dependencies 
between the variables. Our test then boils down to testing for structural breaks in the SVAR model. As the theoretical part of this paper shows, such breaks are identified with the existence of contagion between the variables.

In the empirical part of the paper, we apply our test to the eurozone government bond spreads over Germany. The selected bond maturity is ten years, so the spreads measure the markets' perception of the governments' default risk. Our empirical question is then whether or not there was transmission of default risk in the eurozone government bonds during the beginning of the euro debt crisis. The beginning of the crisis is dated to July 2007. The countries that we consider are Ireland, Greece, Spain, Italy, and Portugal. The analysis finds evidence of contagion. Furthermore, by using what is here called mixture probability weighted correlation coefficients between the spreads, it appears that there was transmission of default risk especially from the Greek bond to those of the others.

The model diagnostic analysis reveals that our model describes the data relatively well. The main shortcoming is the still remaining evidence of conditional heteroskedasticity in the residuals. Better modeling in the changing volatility of the spreads would be an interesting topic for future research. Alternatively, as our analysis uses the daily data, using some lower frequency might be a good idea. However, our model is relatively large. So, estimating it would probably require longer sample period.

Finally, because our contagion test is based on the mainstream empirical strategy to detect contagion, that of discerning contagion from interdependence, let us say a few word about this approach. The main strength of the strategy is that it is is free from economic theory. However, this can also be seen as the strategy's main weakness because, free from free from economic theory, our model is not really able to explain contagion. For such purposes, one needs to estimate one of the proposed theoretical models of contagion. Our model can simply detect any contagion in variables. 


\section{References}

Allen, F., and D. Gale (2000): "Financial Contagion," Journal of Political Economy, 108(1).

Billio, M., and M. Caporin (2010): "Market linkages, variance spillover, and correlation stability: Empirical evidence of financial contagion," Computational Statistics and Data Analysis, 54(11).

Calvo, G. A., and E. G. Mendoza (2000): "Rational contagion and the globalization of securities markets," Journal of International Economics, 51(1).

Calvo, S., and C. Reinhart (1996): "Capital Flows to Latin America - Is There Evidence of Contagion Effects?," World Bank: Policy Research Working Paper, (1619).

Caporale, G. M., A. Cipollini, and P. O. Demetriades (2005): "Monetary policy and the exchange rate during the Asian crisis: identification through heteroscedasticity," Journal of International Money and Finance, 24(1).

Caporale, G. M., A. Cipollini, and N. Spagnolo (2005): "Testing for contagion: a conditional correlation analysis," Journal of Empirical Finance, 12(3).

Corsetti, G., M. Pericoli, and M. Sbracia (2005): "Some Contagion, Some Interdependence: More Pitfalls in Tests of Contagion," Journal of International Money and Finance, 24(8).

Dornbusch, R., Y. C. Park, and S. Claessens (2000): "Contagion: Understanding How It Spreads," The World Bank Research Observer, 15(2).

Dungey, M., R. Fry, B. Gonzalez-Hermosillo, and V. L. Martin (2005): "Empirical modelling of contagion: a review of methodologies," Quantitative Finance, 5(1).

Dunn, P. K., and G. K. Smyth (1996): "Randomized Quantile Residuals," Journal of Computational and Graphical Statistics, 5(3).

Favero, C. A., and F. Giavazzi (2002): "Is the international propagation of financial shocks non-linear? Evidence from the ERM," Journal of International Economics, 57.

Favero, C. A., and A. Missale (2012): "Sovereign spreads in the eurozone: which prospects for a Eurobond," Economic Policy, 27(70).

Forbes, K. (2012): "The "Big C": Identifying contagion," NBER Working Papers, (18465). 
Forbes, K., and R. Rigobon (2001): "Measuring Contagion: Conceptual and Empirical Issues," in International Financial Contagion, ed. by S. Claessens, and K. Forbes, chap. 3, pp. 44-66. Kluwer Academic Publishers, Norwell, Massachusetts, Chapter available at http://web.mit.edu/ kjforbes/www/ Papers/MeasuringContagion.pdf.

Forbes, K. J., and R. Rigobon (2002): "No Contagion, Only Interdependence: Measuring Stock Market Comovements," The Journal of Finance, 57(5).

Kalliovirta, L. (2012): "Misspecification tests based on quantile residuals," Econometrics Journal, 15(2).

Kalliovirta, L., and P. Saikkonen (2010): "Reliable Residuals for Multivariate Nonlinear Time Series Models," unpublished manuscript.

Kilian, L. (2011): "Structural Vector Autoregression," CEPR Discussion Paper, (8515).

King, M. A., and S. Wadhwani (1990): "Transmission of Volatility between Stock Markets," The Review of Financial Studies, 3(1).

Kiyotaki, N., and J. Moore (2002): "Balance-Sheet Contagion," American Economic Review, Papers and Proceedings, 92(2).

Kodres, L. E., and M. Pritsker (2002): "A Rational Expectation Model of Financial Contagion," The Journal of Finance, 57(2).

Kohonen, A. (2012): "On detection of volatility spillovers in simultaneously open stock markets," HECER Discussion Paper, (346).

Lanne, M., and H. Lütkepohl (2010): "Structural Vector Autoregressions With Nonnormal Residuals," Journal of Business 85 Economic Statistics, 25(1).

Lanne, M., H. Lütkepohl, and K. Maciejowska (2010): "Structural vector autoregressions with Markow switching," Journal of Economic Dynamics 63 Control, $34(2)$.

Lee, S. B., and K. J. Kim (1994): "Does the October 1987 crash strengthen the co-movements among national stock markets?," Review of Financial Economics, (March 22), available at http://www.accessmylibrary.com/ article-1G1-16637672/does-october-1987-crash.html (the link checked November 6, 2012).

Lütkepohl, H. (2007): New Introduction to Multiple Time Series Analysis. Berlin: Springer-Verlag, corr. 2nd printing, 1st edn. 
Masson, P. (1999): "Contagion: macroeconomic models with multiple equilibria," Journal of International Money and Finance, 18(4).

Mendoza, E. G., and V. Quadrini (2010): "Financial globalization, financial crises and contagion," Journal of Monetary Economics, 57(1).

Metiu, N. (2012): "Sovereign risk contagion in the Eurozone," Economic Letters, $117(1)$.

Mody, A., and D. Sandri (2012): "The eurozone crisis: how banks and sovereigns came to be joined at the hip," Economic Policy, 27(70).

Palm, F. C., and P. J. Vlaar (1997): "Simple Diagnostic Procedures for Modeling Financial Time Series," Allgemeines Statistisches Archiv, 81.

Pericoli, M., and M. Sbracia (2003): "A Primer on Financial Contagion," Journal of Economic Surveys, 17(4).

Pesaran, M. H., and A. Pick (2007): "Econometric issues in the analysis of contagion," Journal of Economic Dynamics and Control, 31(4).

Rigobon, R. (2002): "The curse of non-investment grade countries," Journal of Development Economics, 69(2).

Rigobon, R. (2003a): "Identification through heteroskedasticity," Review of Economic and Statistics, 85(4).

(2003b): "On the measurement of international propagation of shocks: is the transmission stable?," Journal of International Economics, 61(2).

Rigobon, R., and B. Sack (2003): "Measuring The Reaction of Monetary Policy to the Stock Market," Quarterly Journal of Economics, 118(2).

\section{Appendices}

\section{A Parameter estimates}

Table 3: Sample period 2005-January 2009: Restricted model (standard errors are in parentheses)

\begin{tabular}{l|ccccc}
\hline & \multicolumn{4}{|c}{ Dependent variable } \\
Explanatory variable & Ireland & Greece & Spain & Italy & Portugal \\
\hline & 22 & & Continued on next page
\end{tabular}


Table 3 - continued from previous page

\begin{tabular}{|c|c|c|c|c|c|}
\hline Constant & $\begin{array}{l}-0.011^{* * *} \\
(0.004)\end{array}$ & $\begin{array}{l}0.002 \\
(0.002)\end{array}$ & $\begin{array}{c}-0.001 \\
(0.002)\end{array}$ & $\begin{array}{l}0.004^{* *} \\
(0.002)\end{array}$ & $\begin{array}{l}0.005 \\
(0.004)\end{array}$ \\
\hline Ireland $(-1)$ & $\begin{array}{l}0.618^{* * *} \\
(0.038)\end{array}$ & $\begin{array}{l}0.003 \\
(0.017)\end{array}$ & $\begin{array}{l}0.004 \\
(0.017)\end{array}$ & $\begin{array}{l}-0.044^{* * *} \\
(0.017)\end{array}$ & $\begin{array}{l}-0.017 \\
(0.024)\end{array}$ \\
\hline Greece $(-1)$ & $\begin{array}{l}0.134 \\
(0.071)\end{array}$ & $\begin{array}{l}0.782^{* * *} \\
(0.040)\end{array}$ & $\begin{array}{l}0.085^{* *} \\
(0.040)\end{array}$ & $\begin{array}{l}0.166^{* * *} \\
(0.038)\end{array}$ & $\begin{array}{l}0.113^{* *} \\
(0.056)\end{array}$ \\
\hline $\operatorname{Spain}(-1)$ & $\begin{array}{l}0.081 \\
(0.066)\end{array}$ & $\begin{array}{l}-0.081^{* *} \\
(0.034)\end{array}$ & $\begin{array}{l}0.604^{* * *} \\
(0.037)\end{array}$ & $\begin{array}{l}-0.066 \\
(0.034)\end{array}$ & $\begin{array}{l}0.077 \\
(0.055)\end{array}$ \\
\hline Italy $(-1)$ & $\begin{array}{l}-0.033 \\
(0.075)\end{array}$ & $\begin{array}{l}0.028 \\
(0.036)\end{array}$ & $\begin{array}{l}0.084^{* *} \\
(0.042)\end{array}$ & $\begin{array}{l}0.744^{* * *} \\
(0.039)\end{array}$ & $\begin{array}{l}0.106 \\
(0.062)\end{array}$ \\
\hline Portugal(-1) & $\begin{array}{l}-0.144^{* * *} \\
(0.044)\end{array}$ & $\begin{array}{l}-0.01 \\
(0.020)\end{array}$ & $\begin{array}{l}-0.091^{* * *} \\
(0.025)\end{array}$ & $\begin{array}{l}-0.052^{* *} \\
(0.022)\end{array}$ & $\begin{array}{l}0.462^{* * *} \\
(0.037)\end{array}$ \\
\hline Ireland(-2) & $\begin{array}{l}0.294^{* * *} \\
(0.037)\end{array}$ & $\begin{array}{l}0.014 \\
(0.016)\end{array}$ & $\begin{array}{l}0.016 \\
(0.016)\end{array}$ & $\begin{array}{l}0.054^{* * *} \\
(0.016)\end{array}$ & $\begin{array}{l}0.038 \\
(0.024)\end{array}$ \\
\hline Greece $(-2)$ & $\begin{array}{c}-0.070 \\
(0.066)\end{array}$ & $\begin{array}{l}0.203^{* * *} \\
(0.036)\end{array}$ & $\begin{array}{l}-0.086^{* *} \\
(0.038)\end{array}$ & $\begin{array}{l}-0.154^{\text {*** }} \\
(0.036)\end{array}$ & $\begin{array}{l}-0.116^{* *} \\
(0.055)\end{array}$ \\
\hline Spain $(-2)$ & $\begin{array}{l}0.003 \\
(0.065)\end{array}$ & $\begin{array}{l}0.075^{* *} \\
(0.033)\end{array}$ & $\begin{array}{l}0.351^{* * *} \\
(0.038)\end{array}$ & $\begin{array}{l}0.062 \\
(0.034)\end{array}$ & $\begin{array}{l}-0.055 \\
(0.056)\end{array}$ \\
\hline $\operatorname{Italy}(-2)$ & $\begin{array}{l}0.005 \\
(0.078)\end{array}$ & $\begin{array}{l}-0.005 \\
(0.037)\end{array}$ & $\begin{array}{l}-0.067 \\
(0.043)\end{array}$ & $\begin{array}{l}0.24^{* * *} \\
(0.040)\end{array}$ & $\begin{array}{l}-0.077 \\
(0.064)\end{array}$ \\
\hline Portugal(-2) & $\begin{array}{l}0.135^{\text {*** }} \\
(0.043)\end{array}$ & $\begin{array}{l}-0.017 \\
(0.020)\end{array}$ & $\begin{array}{l}0.083^{* * *} \\
(0.025)\end{array}$ & $\begin{array}{l}0.033 \\
(0.022)\end{array}$ & $\begin{array}{l}0.454^{* * *} \\
(0.037)\end{array}$ \\
\hline Matrix W & Col. 1 & Col. 2 & Col. 3 & Col. 4 & Col. 5 \\
\hline Row 1 & $\begin{array}{l}0.020^{* * *} \\
(0.003)\end{array}$ & $\begin{array}{l}0.005 \\
(0.009)\end{array}$ & $\begin{array}{l}-0.011^{* * *} \\
(0.003)\end{array}$ & $\begin{array}{l}0.008^{* * *} \\
(0.003)\end{array}$ & $\begin{array}{l}0.014^{* * *} \\
(0.002)\end{array}$ \\
\hline Row 2 & $\begin{array}{l}0.002 \\
(0.005)\end{array}$ & $\begin{array}{l}0.012^{* * *} \\
(0.001)\end{array}$ & $\begin{array}{l}0.004^{* *} \\
(0.002)\end{array}$ & $\begin{array}{l}0.004^{* * *} \\
(0.001)\end{array}$ & $\begin{array}{l}0.001 \\
(0.001)\end{array}$ \\
\hline Row 3 & $\begin{array}{l}0.000 \\
(0.001)\end{array}$ & $\begin{array}{l}0.003^{* * *} \\
(0.001)\end{array}$ & $\begin{array}{l}0.000 \\
(0.002)\end{array}$ & $\begin{array}{l}0.016^{* * *} \\
(0.001)\end{array}$ & $\begin{array}{l}0.006^{* *} \\
(0.003)\end{array}$ \\
\hline Row 4 & $\begin{array}{l}-0.001 \\
(0.004)\end{array}$ & $\begin{array}{l}0.01^{* * *} \\
(0.001)\end{array}$ & $\begin{array}{l}-0.007^{* * *} \\
(0.001)\end{array}$ & $\begin{array}{l}0.005^{* *} \\
(0.002)\end{array}$ & $\begin{array}{l}0.006^{* * *} \\
(0.001)\end{array}$ \\
\hline Row 5 & $\begin{array}{l}0.000 \\
(0.003)\end{array}$ & $\begin{array}{l}0.006^{* * *} \\
(0.001)\end{array}$ & $\begin{array}{l}0.000 \\
(0.002)\end{array}$ & $\begin{array}{l}0.005 \\
(0.004)\end{array}$ & $\begin{array}{l}0.026^{* * *} \\
(0.001)\end{array}$ \\
\hline Matrix $\Psi$ & $\begin{array}{l}\boldsymbol{\psi}_{1} \\
37.757^{* * *} \\
(4.485)\end{array}$ & $\begin{array}{l}\boldsymbol{\psi}_{2} \\
30.973^{* * *} \\
(3.783)\end{array}$ & $\begin{array}{l}\psi_{3} \\
15.207^{* * *} \\
(1.808)\end{array}$ & $\begin{array}{l}\boldsymbol{\psi}_{4} \\
7.296^{* * *} \\
(0.897)\end{array}$ & $\begin{array}{l}\boldsymbol{\psi}_{5} \\
4.434^{* * *} \\
(0.540)\end{array}$ \\
\hline Mixture prob. & $\begin{array}{l}\gamma \\
0.824^{* * *} \\
(0.014)\end{array}$ & & & & \\
\hline
\end{tabular}


Table 4: Sample period 2005--January 2009: Unrestricted model (standard errors are in parentheses)

\begin{tabular}{|c|c|c|c|c|c|}
\hline \multirow[b]{2}{*}{ Explanatory variable } & \multicolumn{5}{|c|}{ Dependent variable } \\
\hline & Ireland & Greece & Spain & Italy & Portugal \\
\hline \multirow[t]{2}{*}{ Constant } & $-0.016^{* * *}$ & 0.003 & 0.000 & $0.004^{* *}$ & 0.004 \\
\hline & $(0.004)$ & $(0.002)$ & $(0.002)$ & $(0.002)$ & $(0.004)$ \\
\hline \multirow[t]{2}{*}{ Ireland(-1) } & $0.558^{* * *}$ & 0.010 & 0.009 & -0.027 & -0.007 \\
\hline & $(0.034)$ & $(0.015)$ & $(0.016)$ & $(0.015)$ & $(0.024)$ \\
\hline \multirow[t]{2}{*}{ Greece $(-1)$} & 0.112 & $0.73^{* * *}$ & 0.060 & $0.136^{* * *}$ & 0.091 \\
\hline & $(0.064)$ & $(0.034)$ & $(0.038)$ & $(0.035)$ & $(0.054)$ \\
\hline \multirow[t]{2}{*}{ Spain(-1) } & 0.093 & $-0.061^{* *}$ & $0.622^{* * *}$ & -0.039 & 0.077 \\
\hline & $(0.062)$ & $(0.031)$ & $(0.037)$ & $(0.032)$ & $(0.054)$ \\
\hline \multirow[t]{2}{*}{$\operatorname{Italy}(-1)$} & -0.004 & 0.022 & 0.056 & $0.672^{* * *}$ & 0.069 \\
\hline & $(0.074)$ & $(0.039)$ & $(0.043)$ & $(0.042)$ & $(0.064)$ \\
\hline \multirow[t]{2}{*}{ Portugal(-1) } & $-0.095^{* *}$ & -0.007 & $-0.092^{* * *}$ & -0.031 & $0.486^{* * *}$ \\
\hline & $(0.042)$ & $(0.02)$ & $(0.024)$ & $(0.021)$ & $(0.037)$ \\
\hline \multirow{2}{*}{ Ireland $(-2)$} & $0.326^{* * *}$ & 0.010 & 0.015 & $0.036^{* *}$ & 0.021 \\
\hline & $(0.031)$ & $(0.014)$ & $(0.015)$ & $(0.015)$ & $(0.024)$ \\
\hline \multirow[t]{2}{*}{ Greece(-2) } & -0.048 & $0.255^{* * *}$ & -0.057 & $-0.119^{* * *}$ & -0.086 \\
\hline & $(0.064)$ & $(0.034)$ & $(0.038)$ & $(0.035)$ & $(0.054)$ \\
\hline \multirow[t]{2}{*}{ Spain $(-2)$} & 0.025 & 0.056 & $0.334^{* * *}$ & 0.04 & -0.045 \\
\hline & $(0.061)$ & $(0.03)$ & $(0.037)$ & $(0.032)$ & $(0.054)$ \\
\hline \multirow[t]{2}{*}{$\operatorname{Italy}(-2)$} & -0.015 & -0.007 & -0.046 & $0.305^{* * *}$ & -0.054 \\
\hline & $(0.075)$ & $(0.039)$ & $(0.045)$ & $(0.042)$ & $(0.065)$ \\
\hline \multirow{2}{*}{ Portugal(-2) } & $0.09^{* *}$ & -0.017 & $0.081^{* * *}$ & 0.011 & $0.438^{* * *}$ \\
\hline & $(0.041)$ & $(0.020)$ & $(0.024)$ & $(0.021)$ & $(0.037)$ \\
\hline Matrix $_{1}$ & Col. 1 & Col. 2 & Col. 3 & Col. 4 & Col. 5 \\
\hline \multirow[t]{2}{*}{ Row 1} & $0.017^{* * *}$ & 0.001 & 0.011 & 0.007 & $0.01^{* *}$ \\
\hline & $(0.001)$ & $(0.004)$ & $(0.008)$ & $(0.012)$ & $(0.004)$ \\
\hline \multirow[t]{2}{*}{ Row 2} & 0 & $0.008^{* * *}$ & $0.008^{* * *}$ & -0.002 & -0.002 \\
\hline & $(0.001)$ & $(0.002)$ & $(0.003)$ & $(0.008)$ & $(0.002)$ \\
\hline \multirow[t]{2}{*}{ Row 3} & 0.001 & 0.002 & 0.007 & -0.003 & $0.013^{* * *}$ \\
\hline & $(0.001)$ & $(0.003)$ & $(0.004)$ & $(0.008)$ & $(0.002)$ \\
\hline \multirow[t]{2}{*}{ Row 4} & 0.000 & -0.002 & $0.012^{* * *}$ & 0.002 & 0.002 \\
\hline & $(0.001)$ & $(0.003)$ & $(0.002)$ & $(0.012)$ & $(0.003)$ \\
\hline \multirow[t]{2}{*}{ Row 5} & 0.000 & 0.005 & 0.011 & 0.018 & 0.013 \\
\hline & $(0.001)$ & $(0.005)$ & $(0.018)$ & $(0.012)$ & $(0.007)$ \\
\hline Matrix $_{2}$ & Col. 1 & Col. 2 & Col. 3 & Col. 4 & Col. 5 \\
\hline \multirow[t]{2}{*}{ Row 1} & $0.026^{* * *}$ & -0.005 & $-0.016^{* * *}$ & 0.014 & 0.022 \\
\hline & $(0.008)$ & $(0.042)$ & $(0.006)$ & $(0.024)$ & $(0.016)$ \\
\hline \multirow[t]{2}{*}{ Row 2} & 0.009 & 0.015 & 0.004 & 0.009 & 0.006 \\
\hline & $(0.024)$ & $(0.015)$ & $(0.004)$ & $(0.006)$ & $(0.01)$ \\
\hline \multirow[t]{2}{*}{ Row 3} & 0.001 & 0.002 & 0.002 & $0.022^{* * *}$ & 0.007 \\
\hline & $(0.004)$ & $(0.002)$ & $(0.003)$ & $(0.008)$ & $(0.024)$ \\
\hline \multirow[t]{2}{*}{ Row 4} & 0.001 & $0.013^{* * *}$ & $-0.009^{* * *}$ & 0.012 & 0.012 \\
\hline & $(0.021)$ & $(0.002)$ & $(0.003)$ & $(0.012)$ & $(0.013)$ \\
\hline
\end{tabular}


Table 4 - continued from previous page

\begin{tabular}{l|lllll}
\hline Row 5 & 0.002 & $0.006^{* *}$ & 0.002 & 0.009 & $0.030^{* * *}$ \\
& $(0.010)$ & $(0.003)$ & $(0.004)$ & $(0.032)$ & $(0.010)$ \\
\hline Matrix $\Psi_{1}$ & $\boldsymbol{\psi}_{1}$ & $\boldsymbol{\psi}_{2}$ & $\boldsymbol{\psi}_{3}$ & $\boldsymbol{\psi}_{4}$ & $\boldsymbol{\psi}_{5}$ \\
& $37.855^{* * *}$ & $5.871^{* * *}$ & $3.587^{* * *}$ & $3.104^{* * *}$ & $1.786^{* * *}$ \\
& $(7.98)$ & $(1.243)$ & $(0.789)$ & $(0.691)$ & $(0.495)$ \\
\hline Matrix $\boldsymbol{\Psi}_{2}$ & $\boldsymbol{\psi}_{1}$ & $\boldsymbol{\psi}_{2}$ & $\boldsymbol{\psi}_{3}$ & $\boldsymbol{\psi}_{4}$ & $\boldsymbol{\psi}_{5}$ \\
& $23.828^{* * *}$ & $22.353^{* * *}$ & $11.729^{* * *}$ & $5.143^{* * *}$ & $4.585^{* * *}$ \\
& $(3.929)$ & $(3.585)$ & $(1.894)$ & $(0.895)$ & $(0.769)$ \\
\hline Mixture prob. & $\gamma_{1}$ & & & & \\
& $0.903^{* * *}$ & & & & \\
\hline Mixture prob. & $(0.017)$ & & & & \\
& $\gamma_{2}$ & $0.712^{* * *}$ & & & \\
& $(0.027)$ & & & & \\
\hline
\end{tabular}

NOTE:

Standard errors obtained from the inverse Hessian of the log-likelihood function. $\left({ }^{* *}\right) /\left({ }^{* *}\right)$ indicates statistical significance at $5 \% / 1 \%$ significance level.

The log-likelihood function gets value 17141.0.

Table 5: Sample period 2005-2010: Restricted model (standard errors are in parentheses)

\begin{tabular}{l|lllll}
\hline \multirow{2}{*}{ Explanatory variable } & \multicolumn{5}{|c}{ Dependent variable } \\
& Ireland & Greece & Spain & Italy & Portugal \\
\hline Constant & $-0.007^{* *}$ & 0.003 & $-0.005^{* *}$ & 0.002 & -0.002 \\
& $(0.003)$ & $(0.002)$ & $(0.002)$ & $(0.002)$ & $(0.003)$ \\
Ireland(-1) & $0.784^{* * *}$ & -0.014 & 0.024 & -0.024 & 0.024 \\
& $(0.033)$ & $(0.015)$ & $(0.015)$ & $(0.013)$ & $(0.023)$ \\
Greece(-1) & $0.104^{* * *}$ & $1.021^{* * *}$ & $0.074^{* * *}$ & $0.066^{* * *}$ & $0.129^{* * *}$ \\
& $(0.024)$ & $(0.014)$ & $(0.014)$ & $(0.012)$ & $(0.022)$ \\
Spain(-1) & 0.058 & 0.001 & $0.715^{* * *}$ & -0.032 & 0.068 \\
& $(0.056)$ & $(0.034)$ & $(0.032)$ & $(0.030)$ & $0.050)$ \\
Italy(-1) & 0.043 & -0.034 & 0.027 & $0.854^{* * *}$ & -0.006 \\
Portugal(-1) & $(0.067)$ & $(0.043)$ & $(0.037)$ & $(0.034)$ & $(0.067)$ \\
& $-0.113^{* * *}$ & -0.037 & -0.041 & $-0.045^{* *}$ & $0.657^{* * *}$ \\
Ireland(-2) & $(0.039)$ & $(0.022)$ & $(0.021)$ & $(0.019)$ & $0.037)$ \\
& $0.207^{* * *}$ & 0.018 & -0.014 & $0.027^{* *}$ & -0.022 \\
Greece(-2) & $(0.033)$ & $(0.015)$ & $(0.015)$ & $(0.013)$ & $(0.023)$ \\
Spain(-2) & $-0.093^{* * *}$ & -0.021 & $-0.07^{* * *}$ & $-0.064^{* * *}$ & $-0.114^{* * *}$ \\
& $(0.024)$ & $(0.014)$ & $(0.014)$ & $(0.012)$ & $0.022)$ \\
Italy(-2) & -0.079 & 0.021 & $0.222^{* * *}$ & 0.026 & -0.090 \\
& $(0.055)$ & $(0.034)$ & $(0.032)$ & $(0.03)$ & $(0.05)$ \\
& -0.018 & 0.028 & 0.000 & $0.142^{* * *}$ & 0.021 \\
& $(0.067)$ & $(0.043)$ & $(0.037)$ & $(0.035)$ & $(0.067)$ \\
\hline
\end{tabular}


Table 5 - continued from previous page

\begin{tabular}{|c|c|c|c|c|c|}
\hline Portugal(-2) & $\begin{array}{l}0.102^{* * *} \\
(0.039)\end{array}$ & $\begin{array}{l}0.02 \\
(0.022)\end{array}$ & $\begin{array}{l}0.045^{* *} \\
(0.021)\end{array}$ & $\begin{array}{l}0.040^{* *} \\
(0.019)\end{array}$ & $\begin{array}{l}0.309^{* * *} \\
(0.037)\end{array}$ \\
\hline Matrix W & Col. 1 & Col. 2 & Col. 3 & Col. 4 & Col. 5 \\
\hline Row 1 & $\begin{array}{l}0.006^{* * *} \\
(0.001)\end{array}$ & $\begin{array}{l}-0.027^{* * *} \\
(0.003)\end{array}$ & $\begin{array}{l}-0.003 \\
(0.01)\end{array}$ & $\begin{array}{l}0.019^{* * *} \\
(0.004)\end{array}$ & $\begin{array}{l}-0.004 \\
(0.003)\end{array}$ \\
\hline Row 2 & $\begin{array}{l}0.015^{* * *} \\
(0.001)\end{array}$ & $\begin{array}{l}0.002 \\
(0.002)\end{array}$ & $\begin{array}{l}-0.004 \\
(0.003)\end{array}$ & $\begin{array}{l}0.008^{* * *} \\
(0.002)\end{array}$ & $\begin{array}{l}-0.002^{* *} \\
(0.001)\end{array}$ \\
\hline Row 3 & $\begin{array}{l}0.003^{* * *} \\
(0.001)\end{array}$ & $\begin{array}{l}-0.003 \\
(0.003)\end{array}$ & $\begin{array}{l}-0.011^{* *} \\
(0.005)\end{array}$ & $\begin{array}{l}0.012^{* *} \\
(0.005)\end{array}$ & $\begin{array}{l}0.012^{* * *} \\
(0.002)\end{array}$ \\
\hline Row 4 & $\begin{array}{l}0.002^{* *} \\
(0.001)\end{array}$ & $\begin{array}{l}-0.001 \\
(0.003)\end{array}$ & $\begin{array}{l}-0.01^{* *} \\
(0.005)\end{array}$ & $\begin{array}{l}0.012^{* *} \\
(0.005)\end{array}$ & $\begin{array}{l}-0.006^{* * *} \\
(0.002)\end{array}$ \\
\hline Row 5 & $\begin{array}{l}0.005^{* * *} \\
(0.001)\end{array}$ & $\begin{array}{l}-0.016^{* * *} \\
(0.005)\end{array}$ & $\begin{array}{l}-0.024^{* * *} \\
(0.004)\end{array}$ & $\begin{array}{l}0.003 \\
(0.011)\end{array}$ & $\begin{array}{l}-0.003 \\
(0.003)\end{array}$ \\
\hline Matrix $\Psi$ & $\begin{array}{l}\boldsymbol{\psi}_{1} \\
138.048^{* * *} \\
(11.184)\end{array}$ & $\begin{array}{l}\boldsymbol{\psi}_{2} \\
24.225^{* * *} \\
(1.951)\end{array}$ & $\begin{array}{l}\boldsymbol{\psi}_{3} \\
18.031^{* * *} \\
(1.48)\end{array}$ & $\begin{array}{l}\boldsymbol{\psi}_{4} \\
15.759^{* * *} \\
(1.272)\end{array}$ & $\begin{array}{l}\boldsymbol{\psi}_{5} \\
9.298^{* * *} \\
(0.815)\end{array}$ \\
\hline Mixture prob. & \multicolumn{5}{|l|}{$\begin{array}{l}\gamma \\
0.674^{* * *} \\
(0.013)\end{array}$} \\
\hline $\begin{array}{l}\text { NOTE: } \\
\text { Standard error } \\
(* *) /\left({ }^{* *}\right) \text { indi } \\
\text { The log-likelihn }\end{array}$ & $\begin{array}{l}\text { al s } \\
\text { sets }\end{array}$ & $\begin{array}{l}\text { e at } 5 \\
939.4 \text {. }\end{array}$ & sig & ce leve & \\
\hline
\end{tabular}

Table 6: Sample period 2005-2010: Unrestricted model (standard errors are in parentheses)

\begin{tabular}{l|lllll}
\hline \multirow{2}{*}{ Explanatory variable } & \multicolumn{5}{|c}{ Dependent variable } \\
\hline Constant & Ireland & Greece & Spain & Italy & Portugal \\
\hline Ireland(-1) & $-0.006^{* *}$ & 0.003 & -0.003 & 0.003 & -0.001 \\
& $(0.003)$ & $(0.002)$ & $(0.002)$ & $(0.002)$ & $(0.003)$ \\
Greece(-1) & $0.72^{* * *}$ & 0.006 & 0.014 & -0.019 & 0.011 \\
& $(0.032)$ & $(0.017)$ & $(0.016)$ & $(0.015)$ & $(0.024)$ \\
Spain(-1) & $0.051^{* *}$ & $0.888^{* * *}$ & $0.04^{* * *}$ & $0.043^{* * *}$ & $0.055^{* * *}$ \\
& $(0.026)$ & $(0.023)$ & $(0.015)$ & $(0.014)$ & $(0.021)$ \\
Italy(-1) & -0.017 & -0.054 & $0.677^{* * *}$ & -0.060 & 0.001 \\
& $(0.065)$ & $(0.035)$ & $(0.037)$ & $(0.032)$ & $(0.051)$ \\
Portugal(-1) & 0.072 & 0.012 & 0.021 & $0.800^{* * *}$ & 0.023 \\
& $(0.078)$ & $(0.05)$ & $(0.052)$ & $(0.044)$ & $(0.069)$ \\
Ireland(-2) & -0.047 & -0.004 & -0.029 & -0.009 & $0.697^{* * *}$ \\
Greece(-2) & $(0.04)$ & $(0.023)$ & $(0.024)$ & $(0.021)$ & $(0.039)$ \\
& $0.267^{* * *}$ & -0.007 & -0.006 & 0.024 & -0.008 \\
& $(0.031)$ & $(0.017)$ & $(0.015)$ & $(0.014)$ & $(0.023)$ \\
& -0.044 & $0.114^{* * *}$ & $-0.035^{* *}$ & $-0.042^{* * *}$ & -0.041 \\
& $(0.026)$ & $(0.023)$ & $(0.016)$ & $(0.014)$ & $(0.021)$ \\
\hline
\end{tabular}


Figure 1: 10-years government bond spreads over Germany; US corporate spread (BBB-rated over AAA)

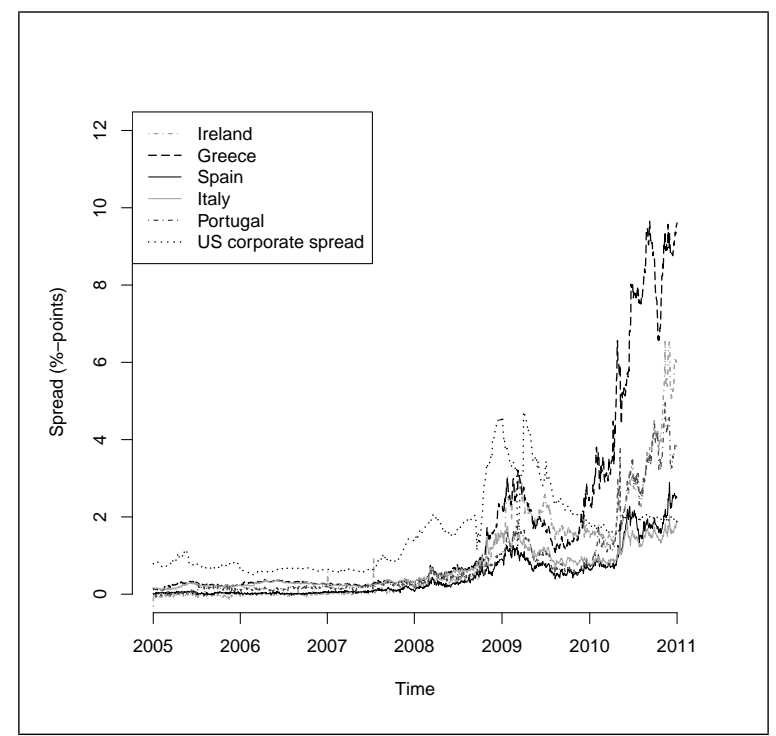

Source: Eurostat, St. Louis Fed's FRED-database, own calculations.

Figure 2: Average six-months rolling correlation coefficients of countries' bond spread with others' spreads

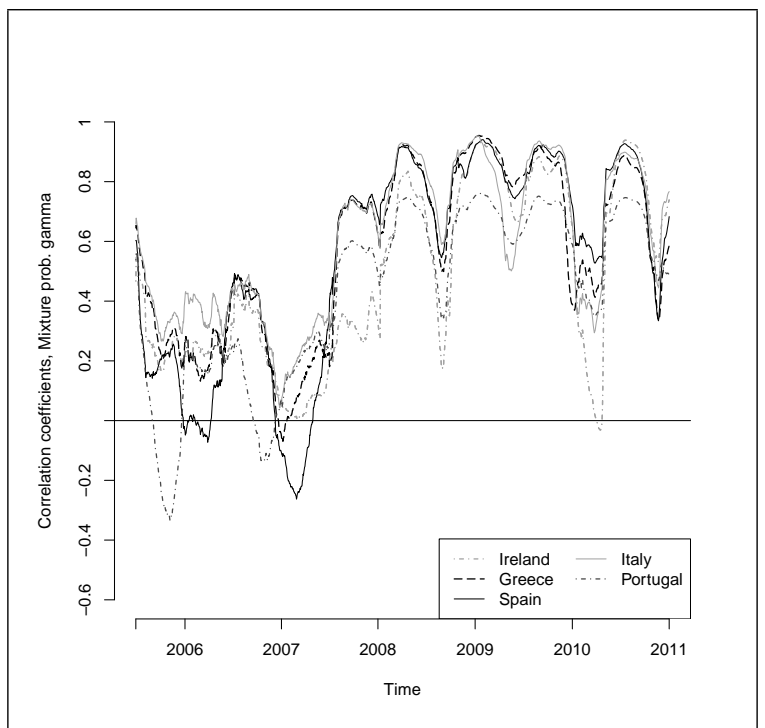

Source: Eurostat, own calculations. 
Figure 3: Quantile residual QQ-plots

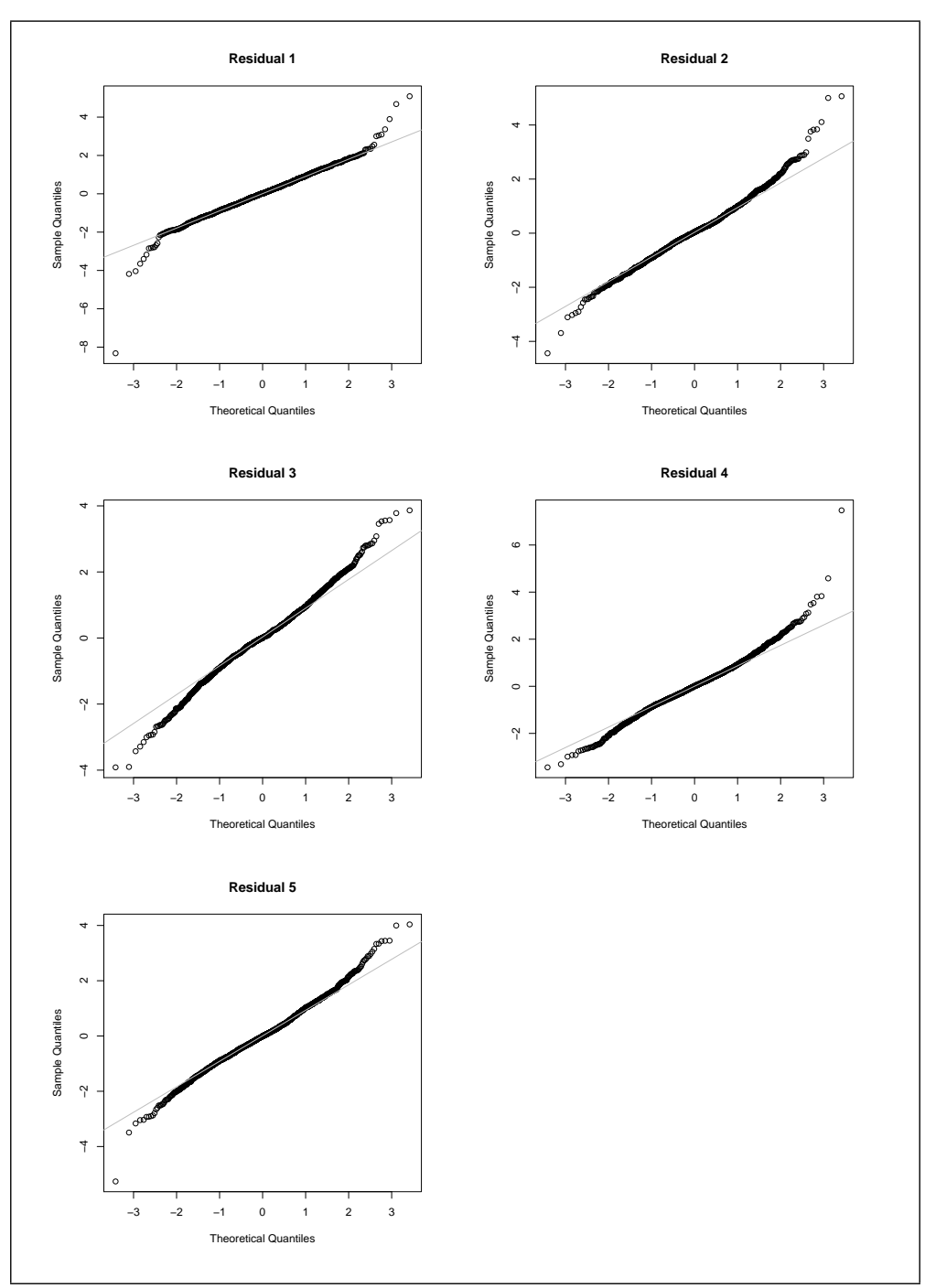

